Article

\title{
Study of the Influence of Magnetite Nanoparticles Supported on Thermally Reduced Graphene Oxide as Filler on the Mechanical and Magnetic Properties of Polypropylene and Polylactic Acid Nanocomposites
}

\author{
Benjamin Constant-Mandiola ${ }^{1}$, Héctor Aguilar-Bolados ${ }^{2}\left(\mathbb{D}\right.$, Julian Geshev $^{3}$ and Raul Quíjada ${ }^{1, *}$ \\ 1 Facultad de Ciencias Físicas y Matemáticas, Universidad de Chile, Beauchef 851, Santiago 8370456, Chile; \\ benjamin.constant@ing.uchile.cl \\ 2 Departamento de Polímeros, Facultad de Ciencias Químicas, Universidad de Concepción, \\ Concepción 3349001, Chile; haguilar@udec.cl \\ 3 Instituto de Física, URFGS, Porto Alegre 91501-970, Brazil; julian@if.ufrgs.br \\ * Correspondence: raquijad@ing.uchile.cl
}

Citation: Constant-Mandiola, B.; Aguilar-Bolados, H.; Geshev, J.; Quíjada, R. Study of the Influence of Magnetite Nanoparticles Supported on Thermally Reduced Graphene Oxide as Filler on the Mechanical and Magnetic Properties of Polypropylene and Polylactic Acid Nanocomposites. Polymers 2021, 13, 1635. https:// doi.org/10.3390/polym13101635

Academic Editor: Ana

María Díez-Pascual

Received: 30 April 2021

Accepted: 11 May 2021

Published: 18 May 2021

Publisher's Note: MDPI stays neutral with regard to jurisdictional claims in published maps and institutional affiliations.

Copyright: (C) 2021 by the authors Licensee MDPI, Basel, Switzerland. This article is an open access article distributed under the terms and conditions of the Creative Commons Attribution (CC BY) license (https:// creativecommons.org/licenses/by/ $4.0 /)$
Abstract: A study addressed to develop new recyclable and/or biodegradable magnetic polymeric materials is reported. The selected matrices were polypropylene (PP) and poly (lactic acid) (PLA). As known, PP corresponds to a non-polar homo-chain polymer and a commodity, while PLA is a biodegradable polar hetero-chain polymer. To obtain the magnetic nanocomposites, magnetite supported on thermally reduced graphene oxide ( $\mathrm{TrGO}: \mathrm{Fe}_{3} \mathrm{O}_{4}$ nanomaterial) to these polymer matrices was added. The $\operatorname{TrGO}: \mathrm{Fe}_{3} \mathrm{O}_{4}$ nanomaterials were obtained by a co-precipitation method using two types of TrGO obtained by the reduction at $600{ }^{\circ} \mathrm{C}$ and $1000{ }^{\circ} \mathrm{C}$ of graphite oxide. Two ratios of 2.5:1 and 9.6:1 of the magnetite precursor $\left(\mathrm{FeCl}_{3}\right)$ and $\mathrm{TrGO}$ were used to produce these nanomaterials. Consequently, four types of nanomaterials were obtained and characterized. Nanocomposites were obtained using these nanomaterials as filler by melt mixer method in polypropylene (PP) or polylactic acid (PLA) matrix, the filler contents were 3, 5, and $7 \mathrm{wt} . \%$. Results showed that $\mathrm{TrGO}_{600}$-based nanomaterials presented higher coercivity $(\mathrm{Hc}=8.5 \mathrm{Oe})$ at 9.6:1 ratio than $\mathrm{TrGO}_{1000}$-based nanomaterials $(\mathrm{Hc}=4.2 \mathrm{Oe})$. PLA and PP nanocomposites containing $7 \mathrm{wt} . \%$ of filler presented coercivity of 3.7 and 5.3 Oe, respectively. Theoretical models were used to analyze some relevant experimental results of the nanocomposites such as mechanical and magnetic properties.

Keywords: nanocomposites; magnetic properties; thermally reduced graphene oxide magnetite

\section{Introduction}

The preparation of polymeric nanocomposites based on carbon nanomaterials is an excellent alternative to obtain polymeric materials with enhanced mechanical or electrical properties [1,2]. This is because carbon nanomaterials impart mechanical resistance and electrical conductivity to the soft and electrically insulating polymeric matrix [3-5]. As known, one of the most widely used nanomaterials as fillers is graphene, due to its diversity of properties, such as its high surface area of $2630 \mathrm{~m}^{2} \cdot \mathrm{g}^{-1}$ and high mechanical properties of $1300 \mathrm{GPa}$ [6]. In this respect, the high surface area of graphene allows for use in a wide range of multiple purposes, such as elastomers, thermoplastic, sustainable glassy nanocomposites [7-9] as well as hydrogel-based nanocomposites for environmental remediation, heavy metal absorption, and waste treatment [10-12]. Moreover, the high surface area of graphene allows hosting on its surface different nanomaterials which specific properties, such as magnetic properties [13].

There are several approaches to obtain graphene materials, one of which considers the thermal, photo, or chemical reduction of graphene oxide (GO) [14-19]. Using a modified Hummers' method, GO can be obtained from graphite. However, the residual presence 
of functional groups present in GO gives it some differences compared with pristine graphene [20]. The thermal reduction of GO is considered one of the highest efficiency and least polluting procedures for obtaining graphene materials [14]. The heat used to reduce GO not only favors total or partial elimination of oxygen-functional groups present in the GO but also allows the exfoliation of the graphene sheets to take place [21,22]. The exfoliation favors the drastic increase of the surface area of these types of materials. Consequently, the partial functionalization with oxygen moieties and the high surface area of these graphene materials opens an interesting approach to explore the synthesis and support of different types of nanoparticles on the surface of graphene.

On the other hand, magnetite is an iron oxide, $\mathrm{Fe}_{3} \mathrm{O}_{4}$, which stands out by presenting magnetic properties [23]. Various methods allow the synthesis of magnetite: electrochemistry [24], sol-gel [25], and chemical coprecipitation [26], the latter being more widely used due to its easy scaling up to the industrial level. The coprecipitation method of magnetite is carried out by using as precursors basic aqueous solutions of $\mathrm{FeCl}_{3}$ and $\mathrm{FeCl}_{2}$, as shown in Equation (1) [27].

$$
\mathrm{Fe}^{2+}+2 \mathrm{Fe}^{3+}+8 \mathrm{OH}^{-} \stackrel{\mathrm{H}_{2} \mathrm{O} / \mathrm{NH}_{3}}{\longrightarrow} \mathrm{Fe}_{3} \mathrm{O}_{4}+\mathrm{H}_{2} \mathrm{O}
$$

The synthesis of magnetite can also be performed on nanomaterial surfaces that present a large surface area such as graphene materials. The presence of functional groups favors the nucleation of magnetite on their surface, obtaining a material with magnetic properties [28].

On the other hand, the pollution generated by the $\alpha$-olefin-based thermoplastics polymers has promoted new research with more sustainable polymers such as polylactic acid (PLA), which can be degraded by external agents such as humidity, UV light, and composting, reducing the adverse impact on the environment [29]. However, it is also necessary to find alternatives to recycle nondegradable polymers such as PP and facilitate this process. Obtaining nanocomposites with magnetic properties allows separating and collecting these materials from disposal polymer batches faster using an external magnetic field, facilitating their recycling. The dispersion of the nanoparticles in the polymers depends as much on the nanoparticle-polymer interaction forces as well as on the nanoparticle-nanoparticle interaction forces [30]. Nanoparticles with a higher polarity due to the presence of functional groups or groups with unpaired electrons will have a higher affinity with a polar polymer matrix such as PLA and PA [31]. In the case of nonpolar nanoparticles, they will have a higher affinity with a nonpolar polymer matrix such as PP [5].

Herein, two thermally reduced graphene oxides at 600 and $1000{ }^{\circ} \mathrm{C}$ that have different contents of oxygen functional groups were used as supports of magnetite synthesized by a coprecipitation method. The structure, morphology, and magnetic properties of these supported-magnetite nanoparticles on TrGO were studied. Besides, the influence of these hybrid nanomaterials on the properties of the thermoplastic polymer matrices, namely polypropylene and polylactic acid were studied. These matrices were selected because they are polymers with importance in the industry of thermoplastic polymers. For instance, PP is extensively used in household and industrial applications, consequently it is considered a commodity [32]. Conversely, PLA is far less used for manufacturing low price goods, the PLA's importance stems from its biodegradable character and possesses prospective applications [33]. It is important to mention that PP corresponds to a non-polar homochain polymer, while PLA is a polar hetero-chain polymer. As known, nowadays, there is a significant interest in using biodegradable polymers in the thermoplastic industry. However, in both cases, the study of their preparation and magnetic properties could provide information for understanding the behavior of these nanocomposites. 


\section{Materials and Methods}

\subsection{Materials}

Graphite, sulfuric acid $\left(\mathrm{H}_{2} \mathrm{SO}_{4}, 98 \%\right)$, potassium permanganate $\left(\mathrm{KMnO}_{4}, \geq 99.0 \%\right)$, hydrochloric acid $(\mathrm{HCl}, 37 \%)$, sodium nitrate $\left(\mathrm{NaNO}_{3}, 99.0 \%\right)$, iron(III) chloride hexahydrate $\left(\mathrm{FeCl}_{3} \cdot 6 \mathrm{H}_{2} \mathrm{O}, 97 \%\right)$, iron(II) chloride tetrahydrate $\left(\mathrm{FeCl}_{2} \cdot 4 \mathrm{H}_{2} \mathrm{O}, 98 \%\right)$ and ammonia solution $\left(\mathrm{NH}_{3}, 25 \%\right)$ were supplied by Merck (Kenilworth, NJ, USA). Polypropylene (PP) PH 2621, density $=905 \mathrm{~kg} \cdot \mathrm{m}^{-3}$, molecular weight $=195 \mathrm{Kg} \cdot \mathrm{mol}^{-1}$, melt flow index $=27 \mathrm{~g} / 10 \mathrm{~min}$ $\left(2.16 \mathrm{~kg}, 230^{\circ} \mathrm{C}\right)$ supplied by Petroquim S.A. (Santiago, Chile). Polylactic acid (PLA) 4032D, density $=1240 \mathrm{~kg} \cdot \mathrm{m}^{-3}$, molecular weight $=107.3 \mathrm{Kg} \cdot \mathrm{mol}^{-1}$, melt flow index $=7(2.16 \mathrm{~kg}$, $230^{\circ} \mathrm{C}$ ), supplied by NatureWorks (Minnetonka, Minneapolis, MN, USA). All materials were used as received.

\subsection{Synthesis of $\mathrm{TrGO} / \mathrm{Fe}_{3} \mathrm{O}_{4}$ Nanoparticles}

\subsubsection{Graphene Oxide Synthesis and Thermally Reduction Process}

The graphene oxide (GO) was obtained by a modified Hummers method, which considers the addition of $15 \mathrm{~g}$ of graphite and $7.5 \mathrm{~g}$ of $\mathrm{NaNO}_{3}$ dispersed in $375 \mathrm{~mL}$ of sulfuric acid under constant stirring at $0{ }^{\circ} \mathrm{C}$. The suspension was stirred for $30 \mathrm{~min}$, and then $45 \mathrm{~g}$ of $\mathrm{KMnO}_{4}$ was added slowly in small portions over a period of one hour. Then the suspension was mixed to room temperature and was left to react for $45 \mathrm{~min}$. The mixture was poured carefully into $750 \mathrm{~mL}$ of distilled water, and $675 \mathrm{~mL}$ of $\mathrm{H}_{2} \mathrm{O}_{2}$ (5 vol\%), added with the purpose of removing the excess of $\mathrm{KMnO}_{4}$. The reaction product was washed with $\mathrm{HCl}(26 \%)$ and was filtered several times until the supernatant achieved a $\mathrm{pH}$ ca. 7. Finally, the GO was dried at $80^{\circ} \mathrm{C}$ for $12 \mathrm{~h}$ [34].

For the thermally reduced graphene oxide (TrGO) synthesis, GO was previously dried for $6 \mathrm{~h}$ at $80^{\circ} \mathrm{C}$ under vacuum. A small portion of GO was introduced into a quartz reactor, which was sealed and purged using nitrogen gas. The reactor was slowly heated up $600{ }^{\circ} \mathrm{C}$ or $1000^{\circ} \mathrm{C}$ and the reactor was left for $30 \mathrm{~s}$ at the working temperature. The reactor was then allowed to cool down to room temperature. The thermal shock is the prime requirement to achieve exfoliation and reduction of graphene sheet functional groups [14].

\subsection{2. $\mathrm{TrGO} /$ Magnetite Nanomaterial Synthesis}

The $\mathrm{TrGO} /$ magnetite nanomaterial was synthesized by coprecipitation of $\mathrm{FeCl}_{3} \cdot 6 \mathrm{H}_{2} \mathrm{O}$ and $\mathrm{FeCl}_{2} \cdot 4 \mathrm{H}_{2} \mathrm{O}$ in the presence of $\operatorname{TrGO}_{600}$ or $\operatorname{TrGO}_{1000}$. The aqueous solutions of ferric chloride and ferrous chloride were prepared in a 2:1 mole ratio. Two solutions with different concentrations were used in order to obtain materials with different $\mathrm{FeCl}_{3}$ and $\mathrm{TrGO}_{600}$ or $\mathrm{TrGO}_{1000}$ weight ratios of 2.5:1 and 9.6:1 FeCl $3: \mathrm{TrGO}$, resulting in four samples of nanomaterials: $\left(\mathrm{Mb}_{600}, \mathrm{Mb}_{1000}, \mathrm{Ma}_{600}\right.$, and $\left.\mathrm{Ma}_{1000}\right)$. The preparation of $\mathrm{Mb}_{600}$ and $\mathrm{Mb}_{1000}$ consisted of the addition of $50 \mathrm{mg}$ of $\mathrm{TrGO}_{600}$ (for $\mathrm{Mb}_{600}$ ) or $\mathrm{TrGO}_{1000}$ (for $\mathrm{Mb}_{1000}$ ) to $50 \mathrm{~mL}$ of DI water. These suspensions were ultrasonicated for $1 \mathrm{~h}$, and then $50 \mathrm{~mL}$ of $\mathrm{FeCl}_{3}(125 \mathrm{mg})$ and $\mathrm{FeCl}_{2}(49 \mathrm{mg})$ solution in DI water was added at $80{ }^{\circ} \mathrm{C}$. Similarly, the preparation of $\mathrm{Ma}_{600}$ and $\mathrm{Ma}_{1000}$ considered the addition of $50 \mathrm{mg}$ of $\mathrm{TrGO}_{600}$ (for $\mathrm{Ma}_{600}$ ) or $\mathrm{TrGO}_{600}$ (for $\mathrm{Ma}_{1000}$ ) in $50 \mathrm{~mL}$ of DI water was ultrasonicated for $1 \mathrm{~h}$. Then $50 \mathrm{~mL}$ of $\mathrm{FeCl}_{3}(480 \mathrm{mg})$ and $\mathrm{FeCl}_{2}(188 \mathrm{mg})$ solutions were added at $80{ }^{\circ} \mathrm{C}[28,35,36]$.

After mixing the ferric chloride and ferrous chloride solutions with the TrGO solution, a $25 \%$ ammonia solution was added, increasing the $\mathrm{pH}$ to 10 at $80^{\circ} \mathrm{C}$. This process was carried out under a nitrogen gas flow. The resulting suspensions were stirred for $30 \mathrm{~min}$. The suspensions were cooled at $0{ }^{\circ} \mathrm{C}$ in an ice bath, the nanomaterial was separated using a magnet and was washed three times with DI water, and finally vacuum-dried at $60^{\circ} \mathrm{C}$ for $2 \mathrm{~h}$.

\subsection{Characterization of Nanoparticles}

The different graphene materials were characterized by elemental analysis carried out using a Perkin Elmer MCHNSO/2400 analyzer (Waltham, MA, USA). These materials also were characterized by powder X-ray diffraction (XRD) and were recorded using a 
Siemens D-5000 wide-angle XRD spectrometer (München, Germany) with $\mathrm{Cu}$ K $\alpha$ radiation, operating at $40 \mathrm{kV}$ and $30 \mathrm{~mA}$. The Raman spectroscopy was performed in an inVia Renishaw Raman spectrometer (Wotton-Under-Edge, UK) equipped with a $532 \mathrm{~nm}$ laser at a power of $10 \mathrm{~mW}$. The specific surface areas were analyzed in a Nova Station A analyzer Quantachrome instruments, Anton Paar (Ashland, Wilmington, DE, USA), through the determination of the multi-point Brunauer-Emmett-Teller (BET) plot using nitrogen gas, all curves presented an $R^{2}$ higher than 0.999 [37,38]. Scanning electron microscopy (SEM) studies were performed in an EVO MA10 Carl Zeiss microscope (Jena, Germany) operating at $13.4 \mathrm{kV}$.

The magnetic properties of $\operatorname{TrGO}: \mathrm{Fe}_{3} \mathrm{O}_{4}$ (powder) were measured as a function of the applied magnetic field using an EZ29MicroSense vibrating magnetometer (VSM) with a maximum applied magnetic field of $20 \mathrm{KOe}$. The hysteresis of the magnetization was obtained by varying $\mathrm{H}$ between $+20 \mathrm{KOe}$ and $-20 \mathrm{KOe}$ at room temperature.

\subsection{Preparation of Nanocomposites}

The nanocomposites were prepared by melt mixing in a Brabender Plasticorder double screw mixer (Nordrhein-Westfalen, Germany). The nanocomposites based on PP and PLA nanocomposites were mixed at 190 and $200{ }^{\circ} \mathrm{C}$ for $10 \mathrm{~min}$ using a rotor speed of $110 \mathrm{RPM}$. The filler content in the nanocomposites varied over a range of $3-7 \%$ by weight. The PP, PLA, and $\operatorname{TrGO}: \mathrm{Fe}_{3} \mathrm{O}_{4}$ nanomaterial were dried at $80^{\circ} \mathrm{C}$ for $8 \mathrm{~h}$ prior to being mixed. Then, the nanocomposites were processed in an HP hydraulic press (model D-50) with a heating system, and a water-cooling system. The sample thickness was $1.0 \mathrm{~nm}$ for tensile and magnetic tests.

\subsection{Characterization of Nanocomposites}

The mechanical properties were determined by tensile-strain tests according to the ASTM D638 standard, at a rate of $25 \mathrm{~mm} \cdot \mathrm{min}^{-1}$ at room temperature using an Instron Universal Testing System model 3382, (Norwood, MA, USA). Three specimens were tested for each sample and the average was determined to obtain a representative data dispersion.

The magnetic properties of nanocomposite (films) were measured as a function of the applied magnetic field using an EZ29MicroSense vibrating magnetometer (VSM) (Lowell, MA, USA) with a maximum applied magnetic field of $20 \mathrm{KOe}$. The hysteresis of the magnetization was obtained by varying $\mathrm{H}$ between $+20 \mathrm{KOe}$ and $-20 \mathrm{KOe}$ at room temperature.

\subsection{Theoretical Models}

\subsubsection{Halpin-Tsai Model}

As known, one of the important aspects that influence the mechanical properties of nanocomposites (Young moduli) is the aspect ratio and filler/polymer matrix adhesion. Halpin Tsai model provides information about these features by considering the theoretical moduli of the filler, the matrix, and the experimental moduli of the different nanocomposites. Equations (2) and (3) present the de Halpin Tsai approach [39,40].

$$
\begin{aligned}
& E=E_{M} *\left(1+\eta 2 \alpha V_{f}\right) /\left(1-\eta V_{f}\right) \\
& \eta=\left(E_{f} / E_{M}-1\right) /\left(E_{f} / E_{M}+2 \alpha\right)
\end{aligned}
$$

where $E_{M}$ is the young modulus of the polymer matrix, $E_{f}$ corresponds to the Young modulus of the filler, $\alpha$ is the aspect ratios of the filler nanoparticles, which also considers their geometry and distribution, and $\mathrm{V}_{\mathrm{f}}$ corresponds to the filler volume fraction.

\subsubsection{Langevin Model}

In order to understand the influence of the magnetic properties of the filler on the matrix polymerics, the Langevin model was used for determining the magnetic moment and nanoparticle size [41]. The Langevin equation, as shown in Equation (4), considers 
that each monodomain has magnetic moments randomly oriented, which interact with the external magnetic field.

$$
\mathrm{M}=\mathrm{N} \mu *\left(\operatorname{coth}\left(\mu \mu_{\mathrm{o}} \mathrm{H} / \mathrm{k}_{\mathrm{b}} \mathrm{T}\right)-\mathrm{k}_{\mathrm{b}} \mathrm{T} / \mu \mu_{\mathrm{o}} \mathrm{H}\right)
$$

where $\mu$ is the magnetic moment, $\mu_{\mathrm{o}}$ is the vacuum permittivity, $H$ the external magnetic field, $\mathrm{k}_{\mathrm{b}}$ corresponds to the Boltzman constant, $\mathrm{T}$ is the temperature and $\mathrm{N}$ is the Avogadro number.

\section{Results and Discussion}

\subsection{Characterization of Thermally Reduced Graphene Oxide}

Figure 1a shows the normalized XRD patterns of graphite, GO, $\operatorname{TrGO} 600$, and $\operatorname{TrGO}_{1000}$. Graphite presents an intense diffraction peak at $2 \theta=26.3^{\circ}$, corresponding to the (002) plane which is associated with the interlayer spacing between graphene layers $(0.338 \mathrm{~nm})$. Once the graphite was oxidized, this peak shifted to $2 \theta=12.6^{\circ}$, which indicates an increase in the interlayer distance of $0.702 \mathrm{~nm}$. The increase of the interlayer distance is associated with the incorporation of oxygenated functional groups to the graphitic structure. The thermal reduction process of $\mathrm{GO}$ at 600 or $1000{ }^{\circ} \mathrm{C}$ produced a shift of this peak to $2 \theta=25.1^{\circ}$ and $2 \theta=26.02^{\circ}$, corresponding to the interlayer spacing of $0.35 \mathrm{~nm}$ and $0.34 \mathrm{~nm}$, respectively, as seen in Table 1. Table 1 also presents the chemical composition and the BET surface area of GO, $\mathrm{TrGO}_{600}$, and $\mathrm{TrGO}_{1000}$. In fact, the oxygen contents of $\mathrm{TrGO}_{600}$ and $\mathrm{TrGO}_{1000}$ are lower compared to that of GO $(43.6 \%)$, and they are 15.7 and $8.7 \%$, respectively. The lowest content achieved in $\mathrm{TrGO}_{1000}$ is because a higher temperature favors a more complete reduction. Concerning the BET surface area results of the nanomaterials (Table 1), it is seen that the surface area increases from $69 \mathrm{~m}^{2} \cdot \mathrm{g}^{-1}$ for $\mathrm{GO}$ to 304 and $267 \mathrm{~m}^{2} \cdot \mathrm{g}^{-1}$ for $\mathrm{TrGO}_{600}$ and $\mathrm{TrGO}_{1000}$, respectively. The increase of the surface area proves the effectiveness of the exfoliation of GO by a thermal reduction process.

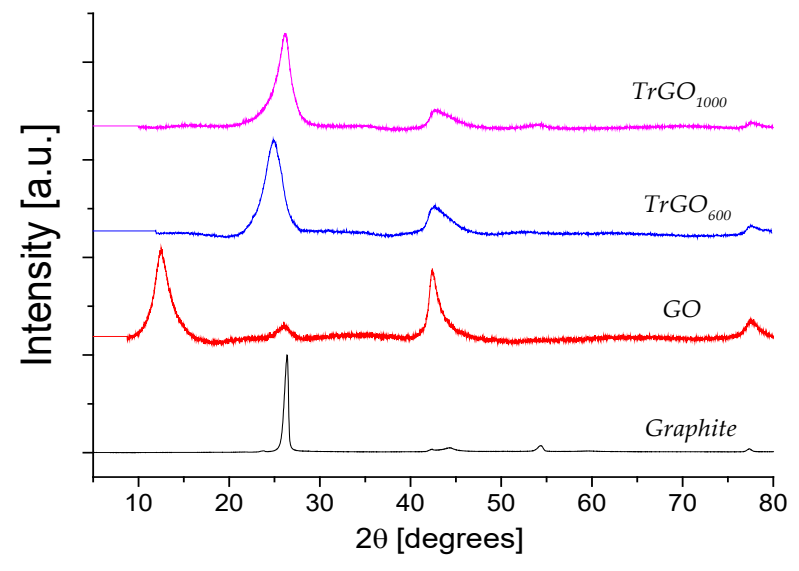

(a)

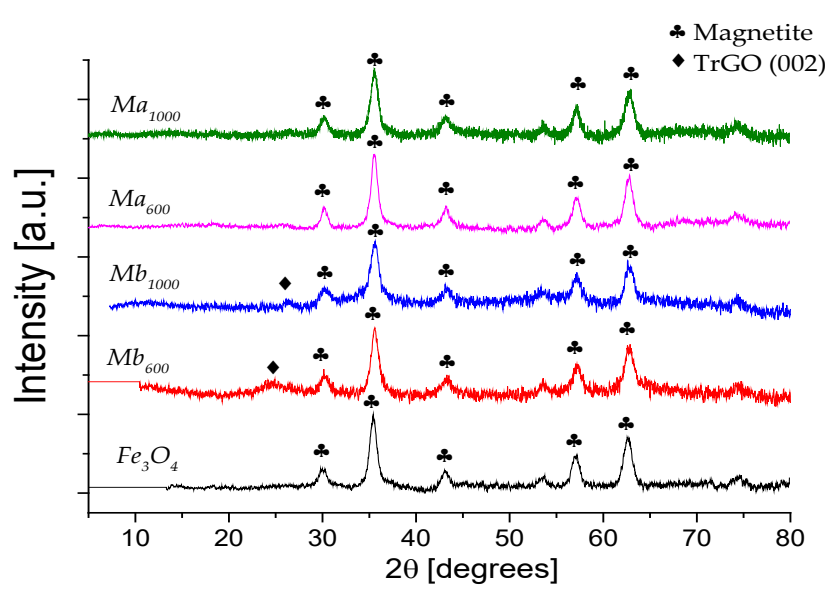

(b)

Figure 1. X-ray diffraction patterns of: (a) graphite, $\mathrm{GO}$, $\operatorname{TrGO} 600$, and $\operatorname{TrGO}_{1000}$ and (b) $\mathrm{Fe}_{3} \mathrm{O}_{4}, \mathrm{Mb}_{600}, \mathrm{Mb}_{1000}, \mathrm{Ma}_{600}$, and $\mathrm{Ma}_{1000}$.

Table 1. Interlayer spacing $\left(\mathrm{d}_{002} \mathrm{~nm}\right)$ and crystal size $\left(\mathrm{L}_{\mathrm{c}} \mathrm{nm}\right)$, elemental analysis, and BET Surface area of $\mathrm{GO}, \mathrm{TrGO}_{600}$, and $\operatorname{TrGO}_{1000}$.

\begin{tabular}{cccccccc}
\hline \multirow{2}{*}{ Sample } & \multicolumn{2}{c}{ XRD } & & \multicolumn{2}{c}{ Elemental Analysis } & \multicolumn{2}{c}{ BET Surface Area } \\
\cline { 2 - 8 } & $\begin{array}{c}\mathbf{d}_{\mathbf{0 0 2}} \\
\mathbf{n m}\end{array}$ & $\begin{array}{c}\mathbf{L}_{\mathbf{c}} \\
\mathbf{n m}\end{array}$ & $\mathbf{\% \mathbf { C }}$ & $\mathbf{\%} \mathbf{H}$ & $\mathbf{\%} \mathbf{N}$ & $\mathbf{\%}$ & $\mathbf{m}^{\mathbf{2}} \cdot \mathbf{g}^{\mathbf{- 1}}$ \\
\hline $\mathrm{GO}$ & 0.702 & 4.08 & 54.4 & 1.9 & 0.1 & 43.6 & 69.7 \\
$\mathrm{TrGO}_{600}$ & 0.350 & 3.42 & 83.9 & 0.3 & 0.1 & 15.7 & 304 \\
$\operatorname{TrGO}_{1000}$ & 0.340 & 4.01 & 90.8 & 0.4 & 0.1 & 8.70 & 267 \\
\hline
\end{tabular}




\subsection{Characterization of $\operatorname{TrGO} / \mathrm{Fe}_{3} \mathrm{O}_{4}$ Nanomaterials}

Figure $1 \mathrm{~b}$ shows the $\mathrm{XRD}$ patterns of $\mathrm{Mb}_{600}, \mathrm{Mb}_{1000}, \mathrm{Ma}_{600}$, and $\mathrm{Ma}_{1000}$ magnetite (Described in Methodology 2.1.3), all of them showing six peaks at the $2 \theta$ angles of $30.2^{\circ}$, $35.4^{\circ}, 43.3^{\circ}, 53.8^{\circ}, 57.2^{\circ}$, and $62.7^{\circ}$. The peak seen at $35.4^{\circ}$ presents the highest intensity, which is characteristic of the magnetite-based structures. This peak probably corresponds to the (311) magnetite plane with a face-centered cubic arrangement. The diffraction pattern of the $\mathrm{TrGO}: \mathrm{Fe}_{3} \mathrm{O}_{4}$ showed the characteristic peaks of $\mathrm{Fe}_{3} \mathrm{O}_{4}$, indicating the successful deposition of $\mathrm{Fe}_{3} \mathrm{O}_{4}$ on the TrGO surface. Moreover, the peak associated with the (002) plane $\left(2 \theta=26.4^{\circ}\right)$ of $\operatorname{TrGO}$ was observed only in the $\mathrm{Mb}_{600}$ and $\mathrm{Mb}_{1000}$ samples as seen in Figure $1 \mathrm{a}$, indicating that the TrGO surface probably has a lower magnetite content.

The crystal size was estimated using the Debye-Scherrer equation, and it was possible to determine that $\mathrm{Fe}_{3} \mathrm{O}_{4}$ had a $19.4 \mathrm{~nm}$ crystal size. Similar values of (311) crystal size of the $\mathrm{Fe}_{3} \mathrm{O}_{4}$-based structure deposited on $\operatorname{TrGO}$ are shown by samples $\mathrm{Mb}_{600}(16.5 \mathrm{~nm})$, $\mathrm{Mb}_{1000}(12.2 \mathrm{~nm}), \mathrm{Ma}_{1000}(16.2 \mathrm{~nm})$, and $\mathrm{Ma}_{600}(19.2 \mathrm{~nm})$. The crystal size of magnetite particles supported on TrGO tends to be comparable to the values reported by Baumgartner et al. [42], who used similar $\mathrm{pH}$, temperature, and reaction time conditions. In addition, A. Zubir et al. demonstrated the formation of a mixed oxide of $\mathrm{Fe}(\mathrm{II})$ and $\mathrm{Fe}(\mathrm{III})$, namely as $\mathrm{Fe}_{3} \mathrm{O}_{4}$ supported on graphene oxide, using a similar method of coprecipitation. This was supported by using X-ray photoelectron spectroscopy for the characterization of these nanomaterials, wherein the disappearing of $\mathrm{Fe} 2 \mathrm{p}_{3 / 2}$ photoelectron line indicated the existence of the $\mathrm{Fe}(\mathrm{II})$ and $\mathrm{Fe}(\mathrm{III})$ species [43].

Figure 2a,b shows the Raman spectra of nanomaterials of $\mathrm{Mb}_{600}, \mathrm{Mb}_{1000}, \mathrm{Ma}_{600}$, and $\mathrm{Ma}_{1000}$. As expected, $D$ and $G$ bands characteristic of graphene materials are seen (Figure 2a). These bands appear at ca. $1350 \mathrm{~cm}^{-1}$ and $1580 \mathrm{~cm}^{-1}$, respectively [44,45]. It is seen that the sample corresponding to $\mathrm{Ma}_{1000}$ presents a Raman redshift, which is associated with the interaction of graphene layers with nanoparticles [46]. This suggests the occurrence of interaction between the Fe-based structure and the graphene oxygen moieties, favoring the nucleation structure on the graphene structure. On the other hand, Figure $2 b$ shows the region of the Raman spectra between $150 \mathrm{~cm}^{-1}$ and $1000 \mathrm{~cm}^{-1}$, presented to study the contribution of magnetite absorption bands. Bands are seen at ca. $212 \mathrm{~cm}^{-1}$, $274 \mathrm{~cm}^{-1}$, and $385 \mathrm{~cm}^{-1}$ [47].

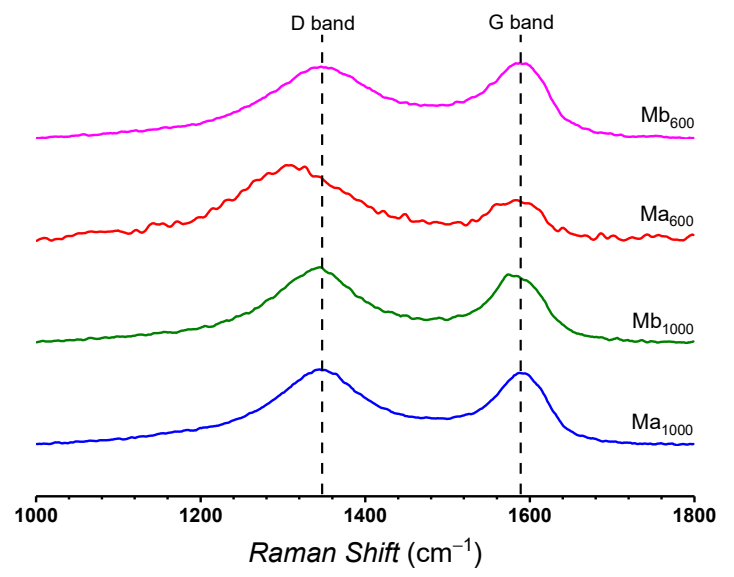

(a)

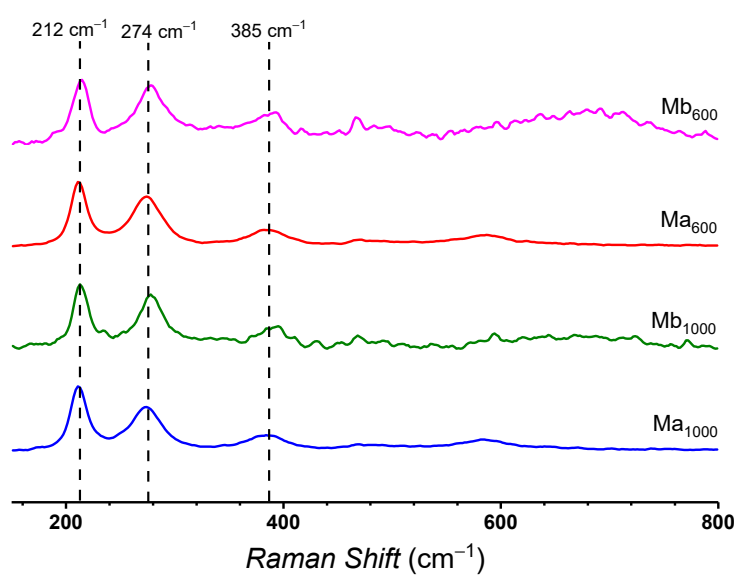

(b)

Figure 2. Raman spectra of $\operatorname{TrGO}$ : (a) and (b) $\operatorname{TrGO} / \mathrm{Fe}_{3} \mathrm{O}_{4}$.

Regarding the $\mathrm{BET}$ analysis, samples $\mathrm{Mb}_{600}, \mathrm{Mb}_{1000}, \mathrm{Ma}_{600}$, and $\mathrm{Ma}_{1000}$ presented surface areas of $143.7,166.8,111.2$, and $123.8 \mathrm{~m}^{2} \cdot \mathrm{g}^{-1}$, respectively. It can therefore be inferred that these decreases depend on the type of graphene used. $\operatorname{TrGO}: \mathrm{Fe}_{3} \mathrm{O}_{4}$ nanomaterials using $\mathrm{TrGO}_{600}$ as support present greater decreases of their surface areas compared to nanomaterials using $\mathrm{TrGO}_{1000}$ as support. $\mathrm{TrGO}_{600}$ presented more oxygen functional 
groups on their surface than $\mathrm{TrGO}_{1000}$, probably favoring the synthesis of magnetite on the surface of $\mathrm{TrGO}_{600}$. In samples with many magnetite nanoparticles, graphene layers are hindered, and their large available surface decreases.

Figure 3 shows SEM images of $\mathrm{TrGO}: \mathrm{Fe}_{3} \mathrm{O}_{4}$ nanomaterials. In the case of nanomaterials of $\mathrm{Mb}_{600}$ and $\mathrm{Mb}_{1000}$ (Figure $3 \mathrm{a}, \mathrm{b}$ ), small magnetite particles are seen on the surface of the graphene flakes and tend to present an amorphous structure. In the case of $\mathrm{Ma}_{600}$ and $\mathrm{Ma}_{1000}$ nanomaterials (Figure 3c,d), they present a highly compacted morphology and heterogeneous distribution of nanoparticle sizes on the surface. The coprecipitation method does not produce homogeneous magnetite particle sizes, so it is possible to find broad size dispersion of magnetite particles on the surface of $\operatorname{TrGO}$ [42]. The appearance of the TrGO: $\mathrm{Fe}_{3} \mathrm{O}_{4}$ nanomaterials indicates that the $\mathrm{Fe}_{3} \mathrm{O}_{4}$ was deposited on the TrGO surfaces, hiding the flakes of this carbon-based nanomaterial. Consequently, the nanomaterials have heterogeneous character; namely, flakes of $\mathrm{TrGO}$, covered by magnetite $\left(\mathrm{Fe}_{3} \mathrm{O}_{4}\right)$.

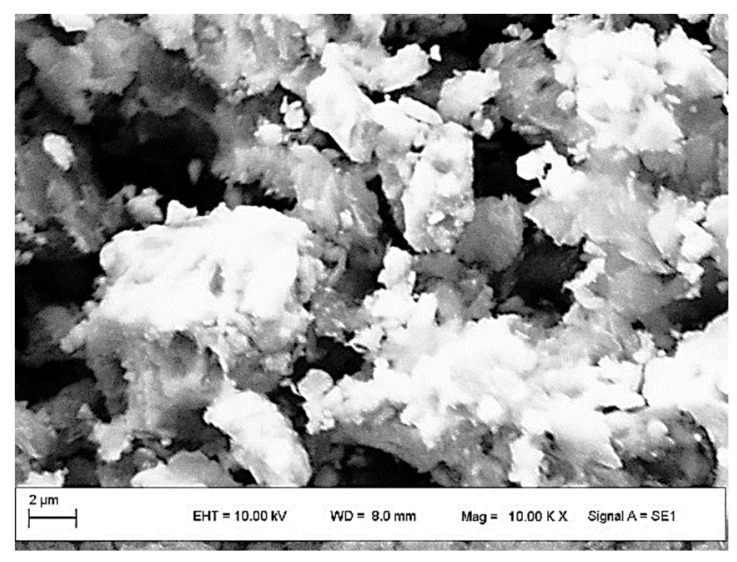

(a)

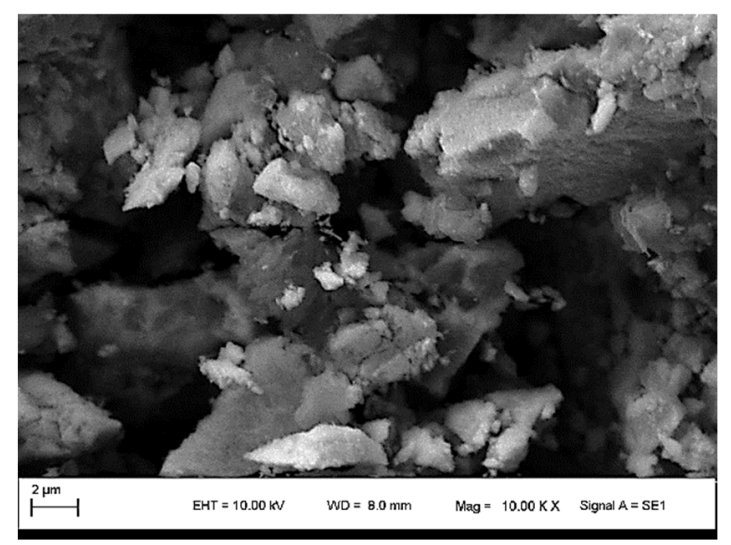

(c)

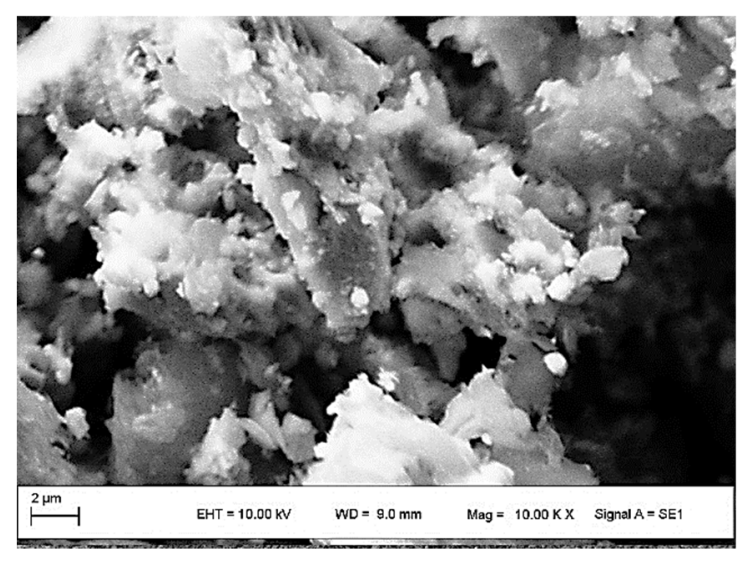

(b)

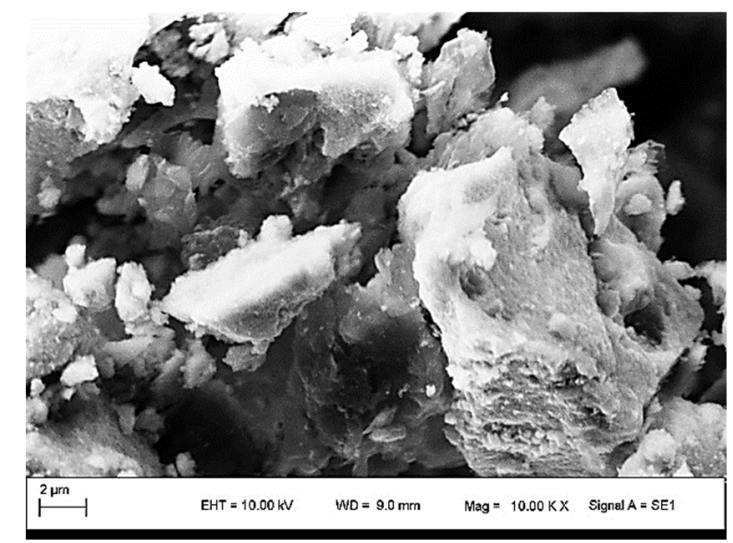

(d)

Figure 3. SEM images of TrGO: $\mathrm{Fe}_{3} \mathrm{O}_{4}$ nanomaterials: (a) $\mathrm{Mb}_{600}$, (b) $\mathrm{Mb}_{1000}$, (c) $\mathrm{Ma}_{600}$, and (d) $\mathrm{Ma}_{1000}$.

\subsection{Magnetic Properties of Nanomaterials}

Figure 4 shows the cycles of magnetic hysteresis curves of $\operatorname{TrGO}: \mathrm{Fe}_{3} \mathrm{O}_{4}$ nanomaterials, where the superparamagnetic behavior of these samples is seen. Nanomaterials $\mathrm{Mb}_{600}$ and $\mathrm{Mb}_{1000}$ presented magnetic saturation $\left(\mathrm{M}_{\mathrm{s}}\right)$ of 37.5 and $39.9 \mathrm{emu} \cdot \mathrm{g}^{-1}$, and coercivity $\left(\mathrm{H}_{\mathrm{c}}\right)$ of $0.373 \mathrm{Oe}$ and $0.023 \mathrm{Oe}$, respectively. On the other hand, nanomaterials $\mathrm{Ma}_{600}$ and $\mathrm{Ma}_{1000}$ presented $\mathrm{M}_{\mathrm{s}}$ values of 55.2 and $63.01 \mathrm{emu} \cdot \mathrm{g}^{-1}$, respectively, and the $\mathrm{H}_{\mathrm{c}}$ were 8.509 and $4.219 \mathrm{Oe}$, respectively. The tendency to increase $\mathrm{M}_{\mathrm{s}}$ and coercivity $\mathrm{H}_{\mathrm{c}}$, which can be attributed to the higher Fe amount used to synthesize the $\mathrm{Ma}_{600}$ and $\mathrm{Ma}_{1000}$ nanomaterials. This can be inferred from the results of X-ray diffraction analysis and Raman spectroscopy. $\mathrm{TrGO}_{600}$-based nanomaterials have lower magnetic susceptibility but greater coercivity 
compared to $\mathrm{TrGO}_{1000}$-based nanomaterials. These results suggest that the coercivity and magnetic susceptibility depend on the crystal size of $\mathrm{Fe}_{3} \mathrm{O}_{4}$.

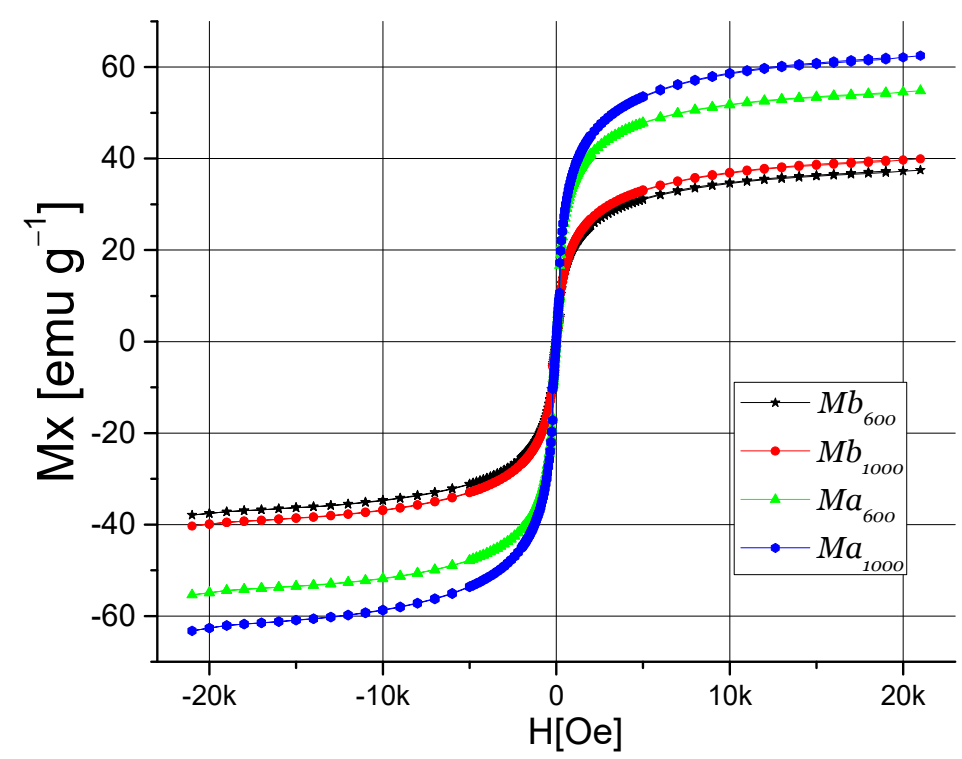

Figure 4. Cycles of Hysteresis magnetic curve of $\operatorname{TrGO}: \mathrm{Fe}_{3} \mathrm{O}_{4}$ powder: $\mathrm{Mb}_{600}, \mathrm{Mb}_{1000}, \mathrm{Ma}_{600}$, and $\mathrm{Ma}_{1000}$.

\subsection{Properties of PP and PLA of Nanocomposites \\ 3.4.1. Mechanical Properties}

Figure 5 shows the Young's modulus of the nanocomposites. In the case of PPTrGO: $\mathrm{Fe}_{3} \mathrm{O}_{4}$ nanocomposites (Figure 5a), it is seen that their Young's moduli have different behaviors depending on the type of filler used and their concentrations. PP nanocomposites containing 5\% $\mathrm{Ma}_{600}$ as filler presented a 21\% increase of Young's modulus. When the filler content was increased to $7 \%$, the $\mathrm{Ma}_{1000}$-based nanocomposites presented a $20 \%$ increase, while the $\mathrm{Ma}_{600}$-based nanocomposites had a decrease of their Young's modulus. The different behaviors of the nanomaterials' Young's modulus are attributed to the affinity that nanomaterials have with the PP matrix. A nonpolar nanomaterial has a better affinity with the nonpolar polymer matrix, favoring the obtaining of homogeneous filler dispersion on the polymer matrix. Conversely, nanomaterials with a polar nature have less affinity with a polar polymer matrix such as PP; consequently, filler agglomerations in the polymer matrix take place. $\mathrm{Mb}_{1000}$ presented a higher affinity with the PP matrix, generating increased mechanical properties. This can be attributed to the fact that $\mathrm{Mb}$ nanocomposites have a lower content of magnetite, which has a polar nature. This probably favors the achievement of a homogeneous dispersion of filler in the PP matrix and an improved filler/polymer interfacial adhesion. Furthermore, the nanoparticle size favored the adhesion of the nanomaterial with the PP matrix. This is reflected in an increase of Young's modulus [48]. However, when the filler content increased to $7 \%$, a drastic reduction of mechanical properties took place.

In the case of PLA-TrGO: $\mathrm{Fe}_{3} \mathrm{O}_{4}$ nanocomposites (Figure $5 \mathrm{~b}$ ), it is seen that Young's moduli depend on the filler content and its nature. PLA composites containing $5 \%$ filler of $\mathrm{Ma}_{1000}$ exhibited an $11 \%$ increase in Young's modulus. Furthermore, Young's modulus decreases $28 \%$ using a $7 \%$ filler of the same nanomaterials. There are two factors that likely can explain the behavior of the mechanical properties of PLA-TrGO: $\mathrm{Fe}_{3} \mathrm{O}_{4}$, namely reprocessing of nanomaterials and agglomeration in the polymer matrix. Probably, the processing of PLA at temperatures close to the melting point, $160-180^{\circ} \mathrm{C}$, generates a partial degradation of the polymer chains, as it was reported in the study of Carrasco et al. [49]. The PLA polymer chains start degrading by releasing methyl groups, causing a decrease in molecular weight, and consequently generating changes in the crystallinity of the polymer. 
This causes a decrease in the mechanical properties, which are linked to the polymer's intermolecular forces $[49,50]$. In addition, the unexpected decrease of Young's moduli of the different nanocomposites also can be related to the heterogeneous nature of the fillers. Magnetite and TrGO likely present weak interactions, and this fact imparts defects in the nanocomposites. As a result, the stiffness of the nanocomposites will decrease in the presence of $\operatorname{TrGO}: \mathrm{Fe}_{3} \mathrm{O}_{4}$, and the brittleness of the nanocomposites will be higher than the neat polymer matrices. This suggests that the use of a binding agent or organic surface modification can be a strategy to increase the interaction between fillers and polymer matrix and to avoid the decrease of the mechanical properties [51-55].

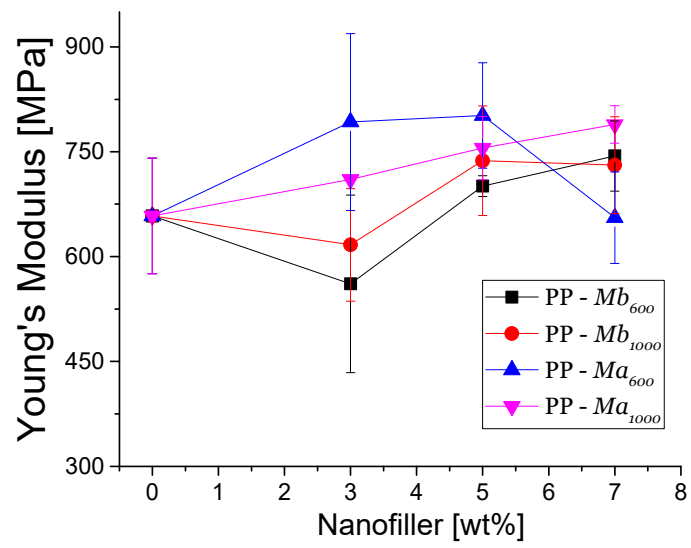

(a)

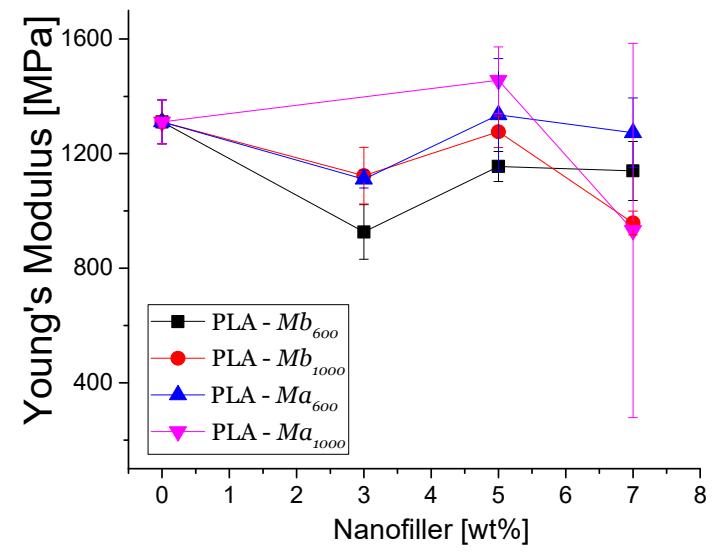

(b)

Figure 5. Young's modulus of nanocomposites: (a) PP-TrGO: $\mathrm{Fe}_{3} \mathrm{O}_{4} ;$ (b) PLA-TrGO: $\mathrm{Fe}_{3} \mathrm{O}_{4}$.

Figure 6 shows the Halpin Tsai-determined theoretical and experimental young moduli as a function of the filler content of nanocomposites based on PP and PLA, respectively. In Figure 6a It is possible to observe the nanocomposites containing $\mathrm{Mb}_{1000}$ and $\mathrm{Ma}_{1000}$ as filler. As seen in this figure, the Halpin Tsai model tends to converge with experimental data, when the aspect ratio is $\alpha=20$ for PPMa $\mathrm{Pa}_{100}$. On the other hand, the estimated aspect ratio of the nanocomposite $\mathrm{PPMb}_{1000}$ is $\alpha=5$. However, the experimental results show a poor correlation with the theoretical data, where nanocomposite filled with $7 \%$ of $\mathrm{Mb}_{1000}$. This may be due to the fact that there are interactions between the nanoparticles that can favor or decrease the adhesion of the nanoparticle with the polymer matrix [56].

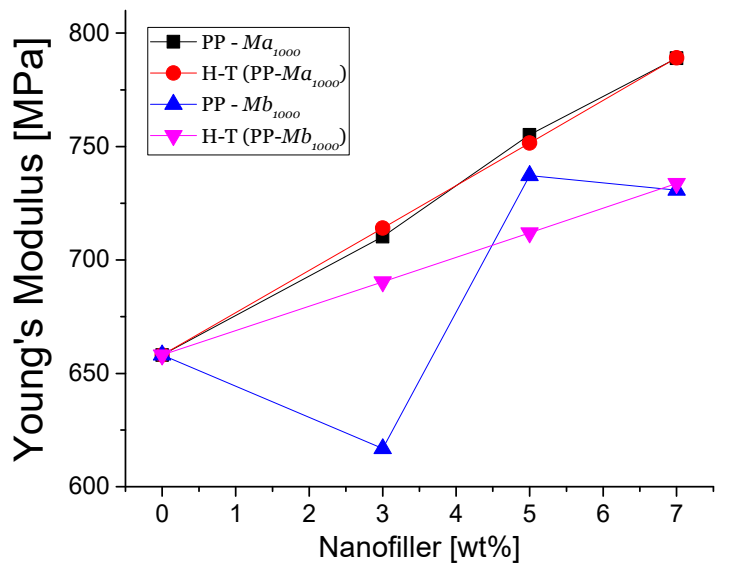

(a)

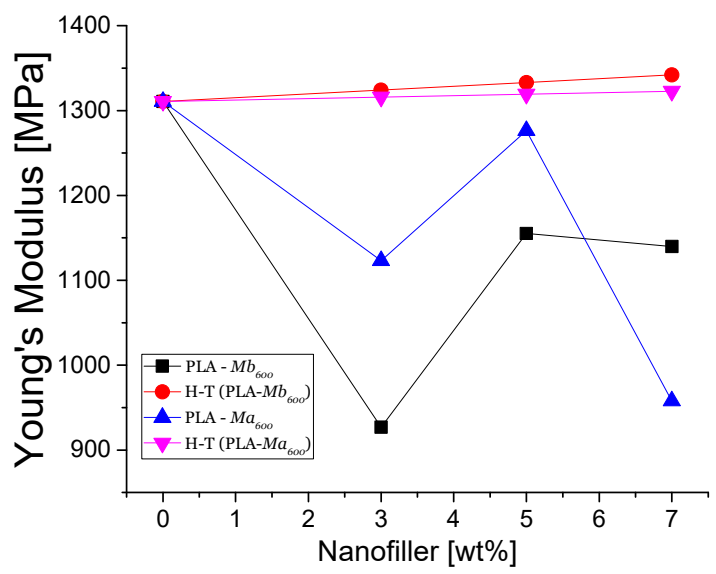

(b)

Figure 6. Halpin Tsai model for nanocomposites of PP-TrGO: $\mathrm{Fe}_{3} \mathrm{O}_{4}(\mathbf{a})$ and PLA-TrGO:Fe $\mathrm{O}_{4}(\mathbf{b})$. 
On the other hand, in Figure 6b, the data of Young's modulus of PLA with filling of $\mathrm{Mb}_{600}$ and $\mathrm{Ma}_{600}$ with the Halpin Tsai model are shown as a function of the filler content. It is possible to observe that the theoretical data do not fit with the experimental results when $\alpha=1$ is used. This suggests that the adhesion of the PLA with nanofiller is low. Consequently, the experimental Young moduli of nanocomposite are lower than the expected values [57].

\subsubsection{Magnetic Properties}

Figure 7 shows the magnetic hysteresis cycles of PP and PLA nanocomposites with nanomaterials of $\mathrm{Mb}_{600}$ and $\mathrm{Mb}_{1000}$ as a filler with a content of 3, 5, and $7 \mathrm{wt} . \%$. In the case of PP nanocomposites (Figure 7a), it was found $\mathrm{M}_{\mathrm{s}}$ value of $3.21 \mathrm{emu} \cdot \mathrm{g}^{-1}$ and a $\mathrm{H}_{\mathrm{c}}$ of 0.24 Oe using $\mathrm{Mb}_{600}$ with $7 \mathrm{wt} . \%$ filler. These data agree with the mechanical properties found for this nanocomposite with $7 \mathrm{wt} . \%$ filler of where $\mathrm{Mb}_{600}$ presents a decrease of these properties due to the agglomerations of the nanomaterials, favoring the contact between the nanoparticles, allowing that a higher magnetic saturation can be achieved in the nanocomposite.

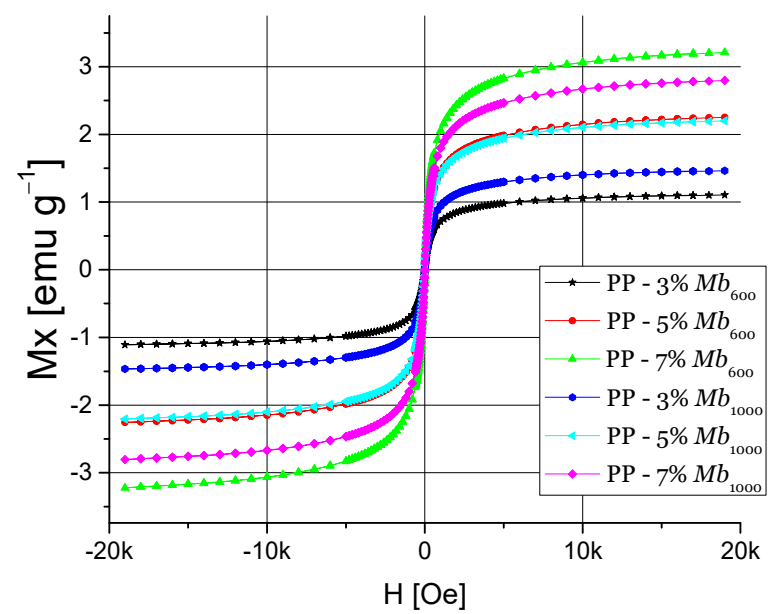

(a)

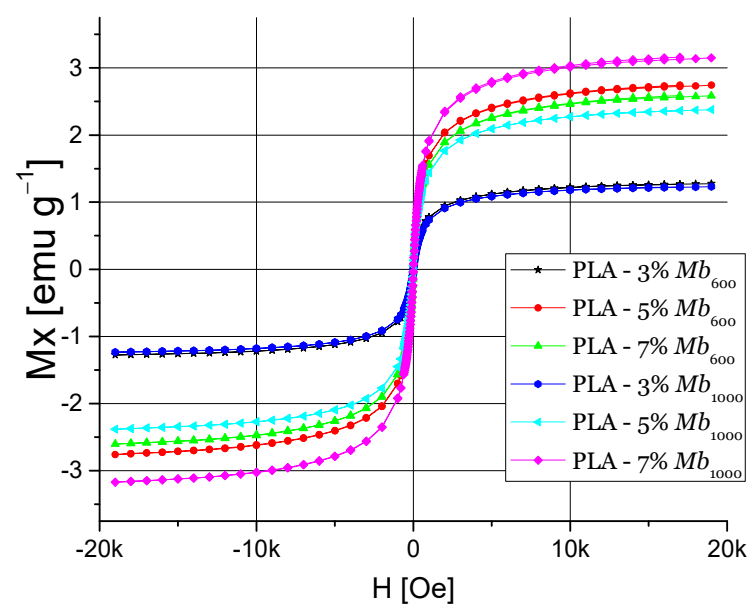

(b)

Figure 7. Magnetic hysteresis cycles: (a) PP:Mb $\mathrm{Mb}_{600}$ and $\mathrm{Mb}_{1000}$ and (b) PLA:Mb 600 and $\mathrm{Mb}_{1000}$ nanocomposites.

In the case of PLA nanocomposites, they present a high $\mathrm{M}_{\mathrm{s}}$ of $3.2 \mathrm{emu} \cdot \mathrm{g}^{-1} \mathrm{using}$ $\mathrm{Mb}_{1000}$ with $7 \%$ filler (Figure $7 \mathrm{~b}$ ). PLA had a weak interaction with the $\mathrm{Mb}_{1000}$ nanoparticles when a $7 \%$ by weight filler was used, increasing the formation of agglomerations due to the interactions between nanomaterials, increasing the magnetic nanocomposite's susceptibility. On the other hand, the coercivity of the PLA nanocomposites is higher than that of the nanoparticles, reaching 0.810 Oe with $\mathrm{Mb}_{600}$ at $7 \%$ filler, more than $200 \%$ of coercivity of the nanoparticle.

Figure 8 shows magnetic hysteresis cycles of PP and PLA nanocomposites with nanomaterials $\mathrm{Ma}_{600}$ and $\mathrm{Ma}_{1000}$ filler. PP nanocomposite magnetic properties showed a high $\mathrm{M}_{\mathrm{s}}$ of $4.71 \mathrm{emu} \cdot \mathrm{g}^{-1}$ using $\mathrm{Ma}_{1000}$ at $7 \%$ filler content and a high $\mathrm{H}_{\mathrm{c}}$ of 5.35 using $\mathrm{Ma}_{600}$ at $7 \%$ filler (Figure 8a). $\mathrm{Ma}_{1000}$ presents a greater magnetic susceptibility than $\mathrm{Ma}_{600}$, so the PP nanocomposites based on this nanomaterial presented a higher magnetic susceptibility, and the contact between the nanoparticles with the polymer matrix likely favors the increase of Ms. In the case of PLA nanocomposites, they present a similar behavior as PP nanocomposites, while when using a $7 \mathrm{wt} . \%$ filler of $\mathrm{Ma}_{1000}$ a Ms of $4.8 \mathrm{emu} \cdot \mathrm{g}^{-1}$ and a high $\mathrm{H}_{\mathrm{c}}$ of $3.97 \mathrm{Oe}$ using $5 \mathrm{wt} . \% \mathrm{Ma}_{1000}$ as a filler (Figure 8b). Compared to PP nanocomposites, a difference in magnetic properties is seen due to interactions between the PLA matrix and the magnetite nuclei of the nanomaterials. 


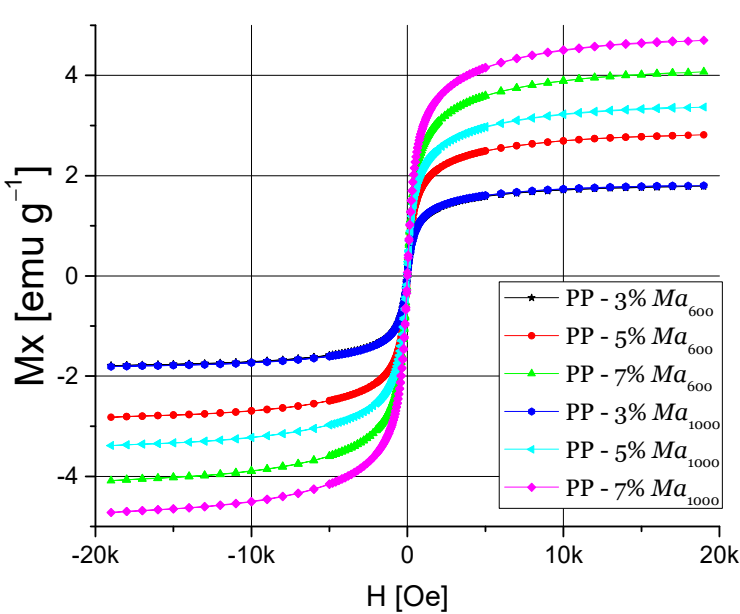

(a)

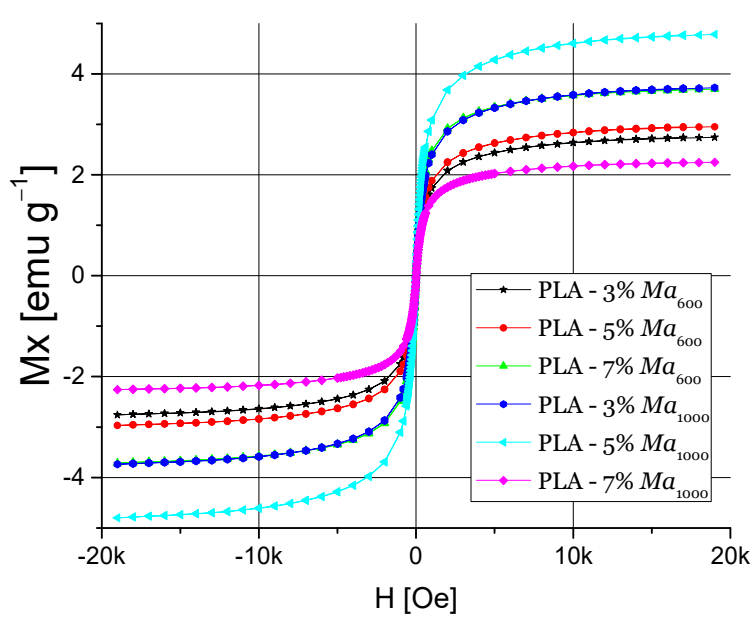

(b)

Figure 8. Magnetic hysteresis cycles: (a) PP:Ma 600 and $\mathrm{Ma}_{1000}$ and (b) PLA:Ma 600 and $\mathrm{Ma}_{1000}$ nanocomposites.

Figure 9 shows results of Langevin model for the nanocomposite, where is observed that the PP-7\% Ma $\mathrm{Ma}_{60}$ nanocomposites curve (Figure 9a) fits with the Langevin model and the estimated particle size is $68 \mathrm{~nm}$ and a magnetic moment of $2747 \mu_{\mathrm{b}}$. On the other hand, it is observed that the experimental curve of the nanocomposite based on $7 \% \mathrm{Ma}_{1000}$ also adjusts with the Langevin model. The calculated magnetic moment is $3113 \mu_{\mathrm{b}}$ and the particle size is $72 \mathrm{~nm}$. It is possible to note that in both cases of PLA nanocomposites presents higher magnetic saturation than those of PP-based nanocomposites, which indicates a higher magnetic moment [58]. On the other hand, there is a correlation of particle size obtained in this theoretical approach with the results presented in the XRD section.

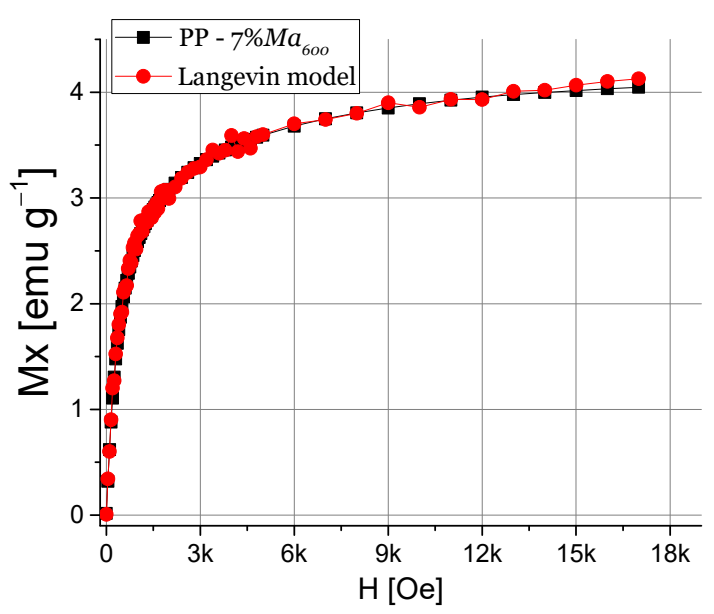

(a)

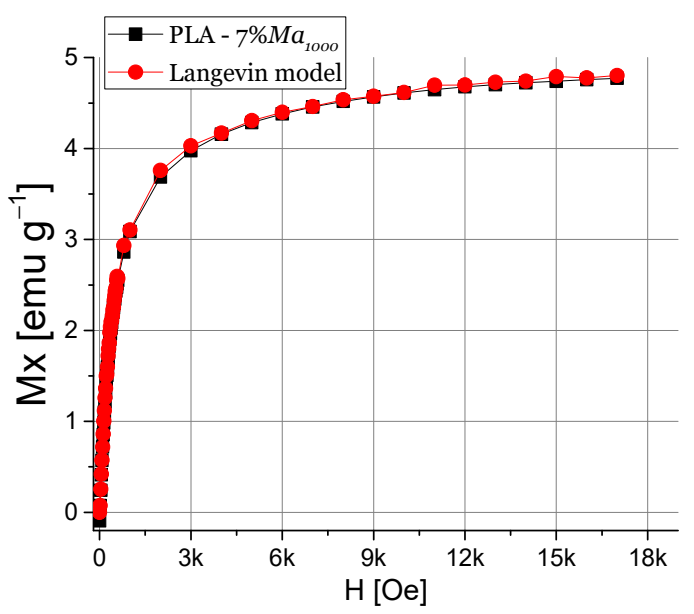

(b)

Figure 9. Langevin model for magnetic properties of PP-TrGO:Fe $\mathrm{O}_{4}(\mathbf{a})$ and PLA-TrGO: $\mathrm{Fe}_{3} \mathrm{O}_{4}(\mathbf{b})$.

\section{Conclusions}

PP and PLA nanocomposites with $\operatorname{TrGO}: \mathrm{Fe}_{3} \mathrm{O}_{4}$ as filler were prepared by melt mixing. $\mathrm{TrGO}_{600}$ has a greater number of functional groups, a larger surface area, and lower content of structural defects than $\operatorname{TrGO}_{1000}$, favoring the nucleation of ferric oxides (magnetite) in its surface, obtaining an average particle size of $18.1 \mathrm{~nm}$ and presenting a higher coercivity of 8.5 Oe. Nanomaterials of $\mathrm{Ma}_{600}$ and $\mathrm{Ma}_{1000}$ (high concentration of $\mathrm{Fe}$ ) have higher magnetic susceptibility and coercivity than $\mathrm{Mb}_{600}$ and $\mathrm{Mb}_{1000}$. This was attributed to increased magnetite nucleation in graphene structures, covering their entire surface. The highest coercivity (5.3 Oe) observed was shown for PP nanocomposite using a 7\% filler 
content of Ma600. In the case of PLA nanocomposite, the highest coercivity value was 3.9 Oe using $7 \%$ filler content of Ma1000. Langevin model was used in magnetic properties to estimate the momentum magnetic and nanoparticle size. All models fit magnetic properties, where PLA with $7 \%$ of Ma600 presented high momentum magnetic of $3113 \mu_{\mathrm{b}}$ and the particle size of $72 \mathrm{~nm}$. On the other hand, the Halpin Tsai model was used to predict the aspect ratio of the nanocomposite by using the mechanical properties, only for PP with Ma1000 showed a good fit. While PLA nanocomposite did not fit properly. The decrease of the mechanical properties of matrices as a result of the addition of the filler can be related to the heterogeneous nature of the fillers based on magnetite and $\operatorname{TrGO}$. The weak interaction between the magnetite and TrGO imparts defects in the nanocomposites. The results of this research provide evidence about the magnetic properties of nanocomposites based on recyclable or biodegradable thermoplastic polymers and shed light on the challenges to obtain magnetic polymer nanocomposites with proper mechanical properties performance.

Author Contributions: Conceptualization, B.C.-M., H.A.-B. and R.Q.; Methodology, B.C.-M. and J.G.; Investigation, B.C.-M. and J.G.; Writing-Original Draft, B.C.-M. and H.A.-B.; Writing-Review \& Editing, B.C.-M., H.A.-B. and R.Q.; Resources, R.Q. All authors have read and agreed to the published version of the manuscript.

Funding: This research was supported by the Chilean Agency for Research and Development (ANID) under the FONDECYT project $N^{\circ}$ 1191642. Also, we acknowledge Professor Carlos Bergmann, from the Departamento de Engenharia dos Materiais, for providing some characterization of samples.

Institutional Review Board Statement: Not applicable.

Informed Consent Statement: Not applicable.

Data Availability Statement: Data are contained within the article.

Conflicts of Interest: The authors declare no conflict of interest.

\section{References}

1. Garzón, C.; Palza, H. Electrical behavior of polypropylene composites melt mixed with carbon-based particles: Effect of the kind of particle and annealing process. Compos. Sci. Technol. 2014, 99, 117-123. [CrossRef]

2. Méndez, R.; Constant, B.; Garzon, C.; Nisar, M.; Nachtigall, S.M.B.; Quijada, R. Barrier, mechanical and conductive properties of polycaprolactam nanocomposites containing carbon-based particles: Effect of the kind of particle. Polymer (Guildford) 2017, 130, 10-16. [CrossRef]

3. Aguilar-Bolados, H.; Lopez-Manchado, M.A.; Brasero, J.; Avilés, F.; Yazdani-Pedram, M. Effect of the morphology of thermally reduced graphite oxide on the mechanical and electrical properties of natural rubber nanocomposites. Compos. Part B Eng. 2016, 87, 350-356. [CrossRef]

4. Gao, Y.; Picot, O.T.; Bilotti, E.; Peijs, T. Influence of filler size on the properties of poly(lactic acid) (PLA)/graphene nanoplatelet (GNP) nanocomposites. Eur. Polym. J. 2017, 86, 117-131. [CrossRef]

5. Gómez, M.; Díaz, A.; Reyes, P.; Yazdani-Pedram, M.; Bohrz Nachtigall, S.M.; Palza, H.; Quijada, R. Effect of thermally reduced graphene oxides obtained at different temperatures on the barrier and mechanical properties of polypropylene/TRGO and polyamide-6/TRGO nanocomposites. Polym. Compos. 2019, 40, E1746-E1756. [CrossRef]

6. Kim, H.; Abdala, A.A.; Macosko, C.W. Graphene/Polymer Nanocomposites. Macromolecules 2010, 43, 6515-6530. [CrossRef]

7. Aguilar-Bolados, H.; Brasero, J.; Lopez-Manchado, M.A.; Yazdani-Pedram, M. High performance natural rubber/thermally reduced graphite oxide nanocomposites by latex technology. Compos. Part B Eng. 2014, 67, 449-454. [CrossRef]

8. Maldonado-Magnere, S.; Yazdani-Pedram, M.; Aguilar-Bolados, H.; Quijada, R. Thermally Reduced Graphene Oxide/Thermoplastic Polyurethane Nanocomposites: Mechanical and Barrier Properties. Polymers 2021, 13, 85. [CrossRef] [PubMed]

9. Cuenca-Bracamonte, Q.; Yazdani-Pedram, M.; Hernández Santana, M.; Aguilar-Bolados, H. Electrical Properties of Poly(Monomethyl Itaconate)/Few-Layer Functionalized Graphene Oxide/Lithium Ion Nanocomposites. Polymers 2020, 12, 2673. [CrossRef] [PubMed]

10. Alammar, A.; Park, S.-H.; Ibrahim, I.; Arun, D.; Holtzl, T.; Dumée, L.F.; Lim, H.N.; Szekely, G. Architecting neonicotinoidscavenging nanocomposite hydrogels for environmental remediation. Appl. Mater. Today 2020, 21, 100878. [CrossRef]

11. Yap, P.L.; Auyoong, Y.L.; Hassan, K.; Farivar, F.; Tran, D.N.H.; Ma, J.; Losic, D. Multithiol functionalized graphene bio-sponge via photoinitiated thiol-ene click chemistry for efficient heavy metal ions adsorption. Chem. Eng. J. 2020, 395, 124965. [CrossRef]

12. Das, L.; Das, P.; Bhowal, A.; Bhattachariee, C. Synthesis of hybrid hydrogel nano-polymer composite using Graphene oxide, Chitosan and PVA and its application in waste water treatment. Environ. Technol. Innov. 2020, 18, 100664. [CrossRef] 
13. Sharif, F.; Arjmand, M.; Moud, A.A.; Sundararaj, U.; Roberts, E.P.L. Segregated Hybrid Poly(methyl methacrylate)/Graphene/ Magnetite Nanocomposites for Electromagnetic Interference Shielding. ACS Appl. Mater. Interfaces 2017, 9, 14171-14179. [CrossRef] [PubMed]

14. Blanco, C.; Santamarı, R.; Botas, C.; Patricia, A.; Rodrı, F.; Granda, M.; Gutie, M.D.; Mene, R. Critical temperatures in the synthesis of graphene-like materials by thermal exfoliation-Reduction of graphite oxide. Carbon 2013, 52, 476-485. [CrossRef]

15. Botas, C.; Álvarez, P.; Blanco, C.; Gutiérrez, M.D.; Ares, P.; Zamani, R.; Arbiol, J.; Morante, J.R.; Menéndez, R. Tailored graphene materials by chemical reduction of graphene oxides of different atomic structure. RSC Adv. 2012, 2, 9643-9650. [CrossRef]

16. Matsumoto, Y.; Koinuma, M.; Kim, S.Y.; Watanabe, Y.; Taniguchi, T.; Hatakeyama, K.; Tateishi, H.; Ida, S. Simple photoreduction of graphene oxide nanosheet under mild conditions. ACS Appl. Mater. Interfaces 2010, 2, 3461-3466. [CrossRef]

17. Aguilar-Bolados, H.; Vargas-Astudillo, D.; Yazdani-Pedram, M.; Acosta-Villavicencio, G.; Fuentealba, P.; Contreras-Cid, A.; Verdejo, R.; López-Manchado, M.A. Facile and Scalable One-Step Method for Amination of Graphene Using Leuckart Reaction. Chem. Mater. 2017, 29, 6698-6705. [CrossRef]

18. Aguilar-Bolados, H.; Contreras-Cid, A.; Yazdani-Pedram, M.; Acosta-Villavicencio, G.; Flores, M.; Fuentealba, P.; Neira-Carrillo, A.; Verdejo, R.; López-Manchado, M.A. Synthesis of fluorinated graphene oxide by using an easy one-pot deoxyfluorination reaction. J. Colloid Interface Sci. 2018, 524, 219-226. [CrossRef] [PubMed]

19. Aguilar-Bolados, H.; Yazdani-Pedram, M.; Quinteros-Jara, E.; Cuenca-Bracamonte, Q.; Quijada, R.; Carretero-González, J.; Avilés, F.; Lopez-Manchado, M.A.; Verdejo, R. Synthesis of sustainable, lightweight and electrically conductive polymer brushes grafted multi-layer graphene oxide. Polym. Test. 2021, 93, 106986. [CrossRef]

20. Huang, W. Graphene Oxide Nanopapers. In Nanopapers: From Nanochemistry and Nanomanufacturing to Advanced Applications; Elsevier Inc.: Amsterdam, The Netherlands, 2018; pp. 1-26. ISBN 9780323480208.

21. McAllister, M.J.; Li, J.L.; Adamson, D.H.; Schniepp, H.C.; Abdala, A.A.; Liu, J.; Herrera-Alonso, M.; Milius, D.L.; Car, R.; Prud'homme, R.K.; et al. Single sheet functionalized graphene by oxidation and thermal expansion of graphite. Chem. Mater. 2007, 19, 4396-4404. [CrossRef]

22. Schniepp, H.C.; Li, J.L.; McAllister, M.J.; Sai, H.; Herrera-Alonson, M.; Adamson, D.H.; Prud'homme, R.K.; Car, R.; Seville, D.A.; Aksay, I.A. Functionalized single graphene sheets derived from splitting graphite oxide. J. Phys. Chem. B 2006, 110, 8535-8539. [CrossRef] [PubMed]

23. Yang, C.; $\mathrm{Wu}, \mathrm{J} . ; \mathrm{Hou}, \mathrm{Y}_{\mathrm{Fe}} \mathrm{F}_{4}$ nanostructures: Synthesis, growth mechanism, properties and applications. Chem. Commun. 2011, 47, 5130-5141. [CrossRef] [PubMed]

24. Cabrera, L.; Gutierrez, S.; Menendez, N.; Morales, M.P.; Herrasti, P. Magnetite nanoparticles: Electrochemical synthesis and characterization. Electrochim. Acta 2008, 53, 3436-3441. [CrossRef]

25. Xu, J.; Yang, H.; Fu, W.; Du, K.; Sui, Y.; Chen, J.; Zeng, Y.; Li, M.; Zou, G. Preparation and magnetic properties of magnetite nanoparticles by sol-gel method. J. Magn. Magn. Mater. 2007, 309, 307-311. [CrossRef]

26. Valenzuela, R.; Fuentes, M.C.; Parra, C.; Baeza, J.; Duran, N.; Sharma, S.K.; Knobel, M.; Freer, J. Influence of stirring velocity on the synthesis of magnetite nanoparticles $\left(\mathrm{Fe}_{3} \mathrm{O}_{4}\right)$ by the co-precipitation method. J. Alloys Compd. 2009, 488, 227-231. [CrossRef]

27. Petcharoen, K.; Sirivat, A. Synthesis and characterization of magnetite nanoparticles via the chemical co-precipitation method. Mater. Sci. Eng. B Solid State Mater. Adv. Technol. 2012, 177, 421-427. [CrossRef]

28. Hatel, R.; Goumri, M.; Ratier, B.; Baitoul, M. Graphene derivatives $/ \mathrm{Fe}_{3} \mathrm{O}_{4}$ / polymer nanocomposite films: Optical and electrical properties. Mater. Chem. Phys. 2017, 193, 156-163. [CrossRef]

29. Abdelwahab, M.A.; Flynn, A.; Chiou, B.S.; Imam, S.; Orts, W.; Chiellini, E. Thermal, mechanical and morphological characterization of plasticized PLA-PHB blends. Polym. Degrad. Stab. 2012, 97, 1822-1828. [CrossRef]

30. Lamkin-Kennard, K.A.; Popovic, M.B. Molecular and Cellular Level-Applications in Biotechnology and Medicine Addressing Molecular and Cellular Level. In Biomechatronics; Elsevier: Amsterdam, The Netherlands, 2019; pp. 201-233.

31. Hu, C.; Li, Z.; Wang, Y.; Gao, J.; Dai, K.; Zheng, G.; Liu, C.; Shen, C.; Song, H.; Guo, Z. Comparative assessment of the strainsensing behaviors of polylactic acid nanocomposites: Reduced graphene oxide or carbon nanotubes. J. Mater. Chem. C 2017, 5, 2318-2328. [CrossRef]

32. Maier, C.; Calafut, T. 11-Applications. In Plastics Design Library; Maier, C., Calafut, T.B.T.-P., Eds.; William Andrew Publishing: Norwich, NY, USA, 1998; pp. 87-107. ISBN 978-1-884207-58-7.

33. Zhong, Y.; Godwin, P.; Jin, Y.; Xiao, H. Biodegradable polymers and green-based antimicrobial packaging materials: A mini-review. Adv. Ind. Eng. Polym. Res. 2020, 3, 27-35. [CrossRef]

34. Zaaba, N.I.; Foo, K.L.; Hashim, U.; Tan, S.J.; Liu, W.W.; Voon, C.H. Synthesis of Graphene Oxide using Modified Hummers Method: Solvent Influence. Procedia Eng. 2017, 184, 469-477. [CrossRef]

35. Moztahida, M.; Nawaz, M.; Kim, J.; Shahzad, A.; Kim, S.; Jang, J.; Lee, D.S. Reduced graphene oxide-loaded-magnetite: A Fenton-like heterogeneous catalyst for photocatalytic degradation of 2-methylisoborneol. Chem. Eng. J. 2019, 370, 855-865. [CrossRef]

36. Ahn, T.; Kim, J.H.; Yang, H.M.; Lee, J.W.; Kim, J.D. Formation pathways of magnetite nanoparticles by coprecipitation method. J. Phys. Chem. C 2012, 116, 6069-6076. [CrossRef]

37. Brunauer, S.; Emmett, P.H.; Teller, E. Adsorption of Gases in Multimolecular Layers. J. Am. Chem. Soc. 1938, 60, 309-319. [CrossRef] 
38. Walton, K.S.; Snurr, R.Q. Applicability of the BET Method for Determining Surface Areas of Microporous Metal-Organic Frameworks. J. Am. Chem. Soc. 2007, 129, 8552-8556. [CrossRef] [PubMed]

39. Affdl, J.C.H.; Kardos, J.L. The Halpin-Tsai equations: A review. Polym. Eng. Sci. 1976, 16, 344-352. [CrossRef]

40. Zare, Y. Development of Halpin-Tsai model for polymer nanocomposites assuming interphase properties and nanofiller size. Polym. Test. 2016, 51, 69-73. [CrossRef]

41. García-Palacios, J.L.; Lázaro, F.J. Langevin-dynamics study of the dynamical properties of small magnetic particles. Phys. Rev. B Condens. Matter Mater. Phys. 1998, 58, 14937-14958. [CrossRef]

42. Baumgartner, J.; Dey, A.; Bomans, P.H.H.; Le Coadou, C.; Fratzl, P.; Sommerdijk, N.A.J.M.; Faivre, D. Nucleation and growth of magnetite from solution. Nat. Mater. 2013, 12, 310-314. [CrossRef]

43. Zubir, N.A.; Yacou, C.; Motuzas, J.; Zhang, X.; Diniz da Costa, J.C. Structural and functional investigation of graphene oxide-Fe ${ }_{3} \mathrm{O}_{4}$ nanocomposites for the heterogeneous Fenton-like reaction. Sci. Rep. 2014, 4, 4594. [CrossRef]

44. Beams, R.; Gustavo Cançado, L.; Novotny, L. Raman characterization of defects and dopants in graphene. J. Phys. Condens. Matter 2015, 27, 083002. [CrossRef]

45. Ferrari, A.C.; Basko, D.M. Raman spectroscopy as a versatile tool for studying the properties of graphene. Nat. Nanotechnol. 2013, 8, 235-246. [CrossRef]

46. Zheng, X.; Chen, W.; Wang, G.; Yu, Y.; Qin, S.; Fang, J.; Wang, F.; Zhang, X.A. The Raman redshift of graphene impacted by gold nanoparticles. AIP Adv. 2015, 5, 057133. [CrossRef]

47. Chicot, D.; Roudet, F.; Lepingle, V.; Louis, G. Strain gradient plasticity to study hardness behavior of magnetite $\left(\mathrm{Fe}_{3} \mathrm{O}_{4}\right)$ under multicyclic indentation. J. Mater. Res. 2009, 24, 749-759. [CrossRef]

48. Weidenfeller, B.; Riehemann, W.; Lei, Q. Mechanical spectroscopy of polymer-magnetite composites. Mater. Sci. Eng. A 2004, 370, 278-283. [CrossRef]

49. Carrasco, F.; Pagès, P.; Gámez-Pérez, J.; Santana, O.O.; Maspoch, M.L. Processing of poly(lactic acid): Characterization of chemical structure, thermal stability and mechanical properties. Polym. Degrad. Stab. 2010, 95, 116-125. [CrossRef]

50. Marin, P.; Tschan, M.J.-L.; Isnard, F.; Robert, C.; Haquette, P.; Trivelli, X.; Chamoreau, L.; Guérineau, V.; del Rosal, I.; Maron, L.; et al. Polymerization of $\mathrm{rac}$-Lactide Using Achiral Iron Complexes: Access to Thermally Stable Stereocomplexes. Angew. Chem. Int. Ed. 2019, 58, 12585-12589. [CrossRef] [PubMed]

51. Lu, H.; Liang, F.; Gou, J. Nanopaper enabled shape-memory nanocomposite with vertically aligned nickel nanostrand: Controlled synthesis and electrical actuation. Soft Matter 2011, 7, 7416-7423. [CrossRef]

52. Lu, H.; Min Huang, W. Synergistic effect of self-assembled carboxylic acid-functionalized carbon nanotubes and carbon fiber for improved electro-activated polymeric shape-memory nanocomposite. Appl. Phys. Lett. 2013, 102, 231910. [CrossRef]

53. Aguilar, H.; Yazdani-Pedram, M.; Toro, P.; Quijada, R.; López-Manchado, M.Á. Synergic effect of two inorganic fillers on the mechanical and thermal properties of hybrid polypropylene composites. J. Chil. Chem. Soc. 2014, 59, 2468-2473. [CrossRef]

54. Carosio, F.; Kochumalayil, J.; Cuttica, F.; Camino, G.; Berglund, L. Oriented Clay Nanopaper from Biobased ComponentsMechanisms for Superior Fire Protection Properties. ACS Appl. Mater. Interfaces 2015, 7, 5847-5856. [CrossRef]

55. Aguilar-Bolados, H.; Quijada, R.; Yazdani-Pedram, M.; Maldonado-Magnere, S.; Verdejo, R.; Lopez-Manchado, M.A. SEBS-

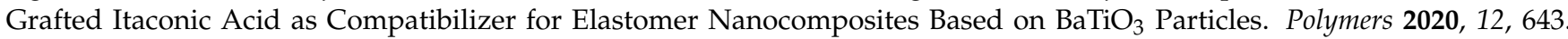
[CrossRef] [PubMed]

56. Kalaitzidou, K.; Fukushima, H.; Miyagawa, H.; Drzal, L.T. Flexural and tensile moduli of polypropylene nanocomposites and comparison of experimental data to Halpin-Tsai and Tandon-Weng models. Polym. Eng. Sci. 2007, 47, 1796-1803. [CrossRef]

57. Lai, S.M.; Wu, S.H.; Lin, G.G.; Don, T.M. Unusual mechanical properties of melt-blended poly(lactic acid) (PLA)/clay nanocomposites. Eur. Polym. J. 2014, 52, 193-206. [CrossRef]

58. Rosensweig, R.E. Heating magnetic fluid with alternating magnetic field. J. Magn. Magn. Mater. 2002, 252, 370-374. [CrossRef] 